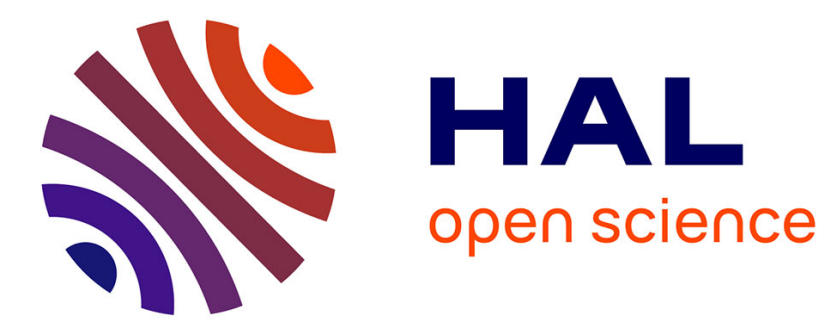

\title{
A REVIEW OF THE REACTION BONDING TECHNIQUE FOR JOINING CERAMICS TO METALS
}

\author{
W. Borbidge, R. Allen, P. Whelan
}

\section{- To cite this version:}

W. Borbidge, R. Allen, P. Whelan. A REVIEW OF THE REACTION BONDING TECHNIQUE FOR JOINING CERAMICS TO METALS. Journal de Physique Colloques, 1986, 47 (C1), pp.C1131-C1-137. 10.1051/jphyscol:1986119 . jpa-00225547

\section{HAL Id: jpa-00225547 https://hal.science/jpa-00225547}

Submitted on 1 Jan 1986

HAL is a multi-disciplinary open access archive for the deposit and dissemination of scientific research documents, whether they are published or not. The documents may come from teaching and research institutions in France or abroad, or from public or private research centers.
L'archive ouverte pluridisciplinaire HAL, est destinée au dépôt et à la diffusion de documents scientifiques de niveau recherche, publiés ou non, émanant des établissements d'enseignement et de recherche français ou étrangers, des laboratoires publics ou privés. 


\title{
A REVIEW OF THE REACTION BONDING TECHNIQUE FOR JOINING CERAMICS TO METALS
}

\author{
W.E. BORBIDGE, R.V. ALLEN and P.T. WHELAN \\ CSIRO, Division of Chemical Physics, P.O. Box 160. Clayton. \\ Victoria, 3168, Australia
}

\begin{abstract}
Résumé - Le scellement réactif est un procédé direct pour former à l'état solide des scellements solides et étanches au vide entre des céramiques et des métaux. Plusieurs domaines d'applications potentielles sont présentés; ils nécessitent de former des liaisons entre de très grands nombres de matériauxles aciers, le cuivre, le titane, le platine et l'or pour les métaux- I'alumine, la PSZ et le nitrure de silicium pour les céramiques.
\end{abstract}

\begin{abstract}
Reaction Bonding is a direct solid-state process for forming strong, vacuum-tight seals between ceramics and metals. Several potential new application areas for the process are discussed, which involve bonds formed between a wide range of materials - metals such as steels, copper, titanium, platinum, and gold, and the ceramics $\mathrm{Al}_{2} \mathrm{O}_{3}, \mathrm{PSz}$ and silicon nitride.
\end{abstract}

\section{I - INTRODUCTION}

Solid-state bonding processes are coming increasingly under study, for the potential advantages they have to offer as a practical joining technique for advanced engineering materials.

The ability to form strong bonds between materials in the solid state is however not a new technology. Thousands of years ago, metals such as silver, gold and iron are known to have been joined by solid-state processes such as hammering or forging. Development has proceeded over the years, to the point where solid-phase welding now covers a range of related industrial processes - cold pressure welding, friction welding, explosive welding and diffusion bonding. All are solid state processes, the basic difference being in the interchange of the three elements of temperature, pressure and time $/ 1,2 /$.

The joining of metals by these solid-state welding processes is widely used and becoming more relevant today, the particular advantage being the ease with which widely dissimilar metals can be joined.

The advent of new engineering materials has posed a challenge to the development of suitable joining techniques, so as to allow these materials to be used to their full potential. In the field of 
ceramics this is especially true. Solid-state metal-ceramic bonding is a teghnique which follows the general principles of solid-phase metal-metal joining techniques, i.e. the application of temperature, pressure and time, in a new way, to form bonds between a wide range of metals and ceramics. These bonds have characteristics ideally suitable for use with these materials - high strength at high operating temperatures, the ability to join materials of differing thermal expansion, and if required, vacuum-tightness of the bonded seal.

\section{II - REACTION BONDING}

The process of solid-state bonding of metals to ceramics has been studied for some years at the CSIRo Division of Chemical Physics, based on original observations by De Bruin, Moodie and Warble $/ 3 /$. This process has come to be known as reaction bonding. A large number of bond combinations have been examined, some of which have been developed commercially into practical applications, such as a $\mathrm{ZrO}_{2}$ based oxygen sensor, and a fast response thermocouple sheath $/ 4 /$.

The bonding of the noble metals $\mathrm{Pt}$ and $\mathrm{Au}$, to $\mathrm{AI}_{2} \mathrm{O}_{3} / 5,6 /$, and $\mathrm{Pd}$ to Mgo have been studied in detail, the latter as a model system using high resolution electron microscopy $/ 7 /$. In this work, the reaction between $\mathrm{Pd}$ and $\mathrm{MgO}$ has been observed directly in the microscope, and it has been established that the reaction proceeds by means of a liquidlike amorphous phase at a temperature lower than the melting point of either material. However micro-diffraction to within $10 \AA$ of the metal/ oxide interface has shown no evidence of any material other than pure Pd or pure Mgo.

Solid-state bonding involving the non-noble metals would seem to take place via a different mechanism altogether, and is often referred to by other workers as diffusion bonding $/ 8 /$, as it tends to involve diffusion of the metal into the ceramic, the formation of reaction zones, and in the cases of nickel and copper with $\mathrm{Al}_{2} \mathrm{O}_{3}$, reactions to form spinel phases at the interface. This is analogous to the solid-phase diffusion bonding processes discussed above, involving metals only.

(i) Bonding using interlayers - with some metals it can be difficult to form reliably strong reaction bonds directly to a ceramic - the ferrous alloys are an important example. So far it has not been established which of the possible causes is responsible $i$.e. thermal expansion mis-match, chemical incompatibility, structural changes in the metal on heating to the bonding temperature, or problems with oxide formation at the bond interface.

We have found that successfuI bonds can be achieved with the use of a suitable metal interlayer between the ceramic and metal to be joined, all bonds still being solid-state however. This effectively combines the old metal-metal solid-phase diffusion bonding with the newer metalceramic solid-state bonding. Suitable interlayer materials have so far been found to be the noble metals $\mathrm{Pt}$ and $\mathrm{Au}$, in the form of thin foils, and also ductile metals like copper. Copper as an interlayer has been found to be particularly useful in facilitating the bonding of stainless steels to ceramics such as $\mathrm{AI}_{2} \mathrm{O}_{3}$ and partially stabilized $\mathrm{ZrO}_{2}$ (PSZ). The ductility of copper aids the bonding process in that the interlayer material can be deformed sufficiently under moderate pressure (3MPa at $\sim 950^{\circ} \mathrm{C}$ bonding temperature) to provide a good contact between itself and ceramic on one side and the steel on the other, without the fine surface finishing of the materials normally required prior to direct reaction bonding of ceramic to metal/5,6/.

Aluminium has been used by others $/ 9 /$ as an interlayer material between 
$\mathrm{Al}_{2} \mathrm{O}_{3}$ and stainless steel. This has the advantage of low bonding temperatures $\left(\sim 600^{\circ} \mathrm{C}\right)$, however the application temperatures are similarly limited. The contact pressures required to bond using aluminium are exceedingly high (50MPa), it has been necessary to deform the metal extensively to break open the oxide layer which is preventing reaction occurring, to expose clean Al to the ceramic. Aluminium also suffers the disadvantage of forming intermetallic layers with stainless steel, which tend to grow in thickness and degrade in strength with time at temperature $19 /$.

\section{III-APPLICATIONS}

Reaction bonding, in combination with solid-phase metal bonding via the use of metal interlayers, has been studied in relation to a number of application areas. These have included the electrical/electronic area, a traditional user of ceramics, and the newer structural applications, where the relatively new engineering ceramics, like PSZ, Syalon and silicon nitrides are coming into prominence. Also of interest is the bio-medical area, where the reaction bonding technique has special benefits to offer.

(i) Electrical/Electronic Applications - Ceramic-metal bonds are required in a wide range of electrical/electronic components. These include insulators, capacitors, discharge housings, $x$-ray tubes, heat sinks, feed-throughs and surge suppressors amongst many others. Almost all of these components require the sealing of copper to an electrically insulating ceramic, usually $\mathrm{Al}_{2} \mathrm{O}_{3}$.

Reaction bonding of copper to these ceramics is readily achieved, the average bond strength being $124 \mathrm{MPa}$ for $\mathrm{Al}_{2} \mathrm{O}_{3}-\mathrm{Cu}-\mathrm{Al}_{2} \mathrm{O}_{3}$ sandwich type specimens (1) bonded at $1040^{\circ} \mathrm{C}$.

The bonding of copper to alumina has been found to be sensitive to impurity levels in the copper, specifically oxygen, and correspondingly sensitive to the bonding atmosphere, in relation to oxygen content. The strength figure quoted above, $124 \mathrm{MPa}$, is achieved for standard electrolytic grade copper sheet, which contains $\sim 0.04 \%$ oxygen as an impurity, and bonds well in an inert atmosphere (pure argon). High conductivity oxygen tiree copper however, with an oxygen content of $0.0002 \%$, tends to bond weakly in argon atmosphere $(<20 \mathrm{MPa})$, however the addition of some oxygen into the atmosphere during the bonding process can improve this strength considerably. For one type of copper foil tested, bond strength was increased from about $10 \mathrm{MPa}$ ( 2 hours at $1040^{\circ} \mathrm{C}$, 2MPa contact pressure) to $223 \mathrm{MPa}$ by flushing a mixture of 0.1 ox oxygen in nitrogen through the furnace during the bonding process.

These results support the mechanism of $\mathrm{Cu}-\mathrm{Al}_{2} \mathrm{O}_{3}$ adherence in the solid state, as proposed by others $/ 10 /$, i.e. the formation of a copper aluminate spinel CuAl $\mathrm{O}_{3}$, arising from reaction between CuO and $\mathrm{Al}_{2} \mathrm{O}_{3}$. This is reported to result in a gradual change of structure at the bond interface, rather than a well-defined boundary.

Another technique for bonding. copper to alumina, known as eutectic bonding, proceeds via a completely different mechanism. This involves the formation of a eutectic phase of $\mathrm{Cu}-\mathrm{Cu}_{2} \mathrm{O}$ at the interface, which wets the ceramic, forming a strong bond. This process requires a minimum bonding temperature of $1065^{\circ} \mathrm{C}$, and very closely controlled atmosphere conditions /11/.

(1) Specimens formed from $998 \mathrm{Al}_{2} \mathrm{O}$ tubing $8 \mathrm{~mm} \mathrm{O.D.} \mathrm{by} 5 \mathrm{~mm}$ I.D., copper discs $0.5 \mathrm{~mm}$ thick. Bonding conditions: 2MPa clamping pressure, argon atmosphere. 
Reaction bonding between $\mathrm{Cu}$ and ceramics is not critical with temperature in this way. Solid-state bonds with copper can be formed down to $\sim 800^{\circ} \mathrm{C}$, however the strengths of reaction bonds do decrease as the bonding temperature is lowered $/ 5 /$.

For the electrical/electronic applications mentioned above, metallizing
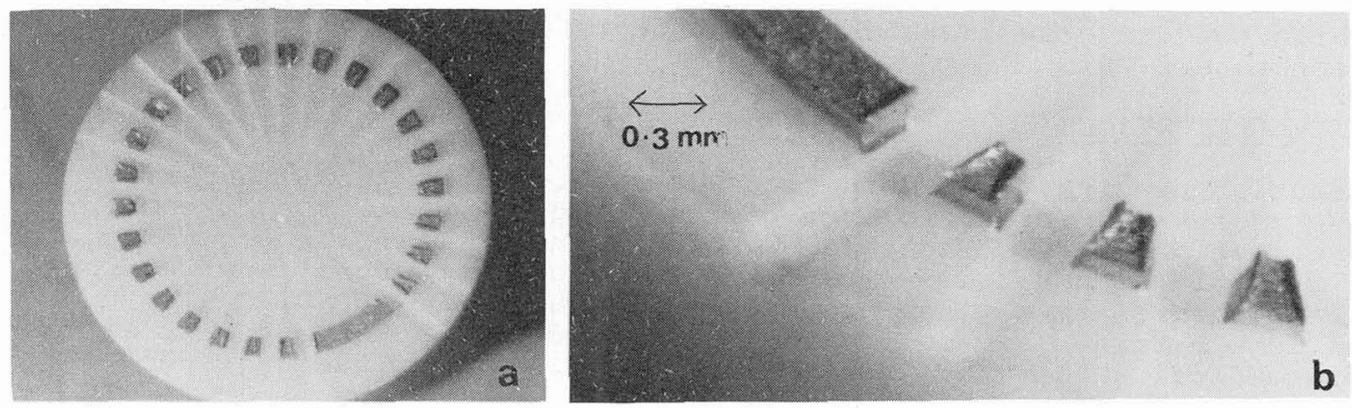

Fig.1. Electrically isolated Pt pads bonded to an $\mathrm{Al}_{2} \mathrm{O}_{3}$ substrate, to form part of a multi-contact electrical device. The Pt ${ }^{3}$ is bonded as a ring (figure 1a), which is later machined to leave the high-profile, hermetically-sealed $\mathrm{Pt}$ pads, as shown in figure $1 \mathrm{~b}$.

and brazing techniques are widely used at present to form the required metal-ceramic seals. These techniques have the advantage over solid-state processes like reaction bonding, in that they are readily adaptable to mass-production techniques. Theix disadvantage however, is that metallized layers have poor electrical and thermal conductivity. with the current demand for higher density and speed of integrated circuit elements, there is a need for improved heat dissipation, and the thermal properties of the metal-ceramic seals are now of great importance. Direct bonding processes like reaction bonding or the eutectic bonding process described above must lead to improvement in thermal properties. For the eutectic bonding process for example, an estimate has been made of $0.02^{\circ} \mathrm{CW}^{-1} \mathrm{~cm}^{2}$ as the contribution of the cu-ceramic interface to the total thermal impedance of a Cu/0.63m $\mathrm{Al}_{2} \mathrm{O}_{3} / \mathrm{Cu}$ sandwich measured at $0.36^{\circ} \mathrm{CW}^{-1} \mathrm{~cm}^{-2} / 11 /$.

Apart from improved heat dissipation across a direct-bonded interface, an advantage of reaction bonding is that the bonds are suitable for applications at high temperatures, above the maximum limits of $\sim 500^{\circ} \mathrm{C}$ for metallized layers. Other metals may need to replace copper in these applications. Platinum-alumina reaction bonds have been tested up to $1100^{\circ} \mathrm{C}$, where vacuum-tightness and strength of $150 \mathrm{MPa}$ (by 4-point bend test) is retained.

Figure 1 shows part of an electrical device where a ring of platinum has been reaction-bonded to an $\mathrm{Al}_{2} \mathrm{O}_{3}$ substrate, the ring later having been cut through at intervals so as to form tiny pt pads arranged in a circular pattern. Variations of this technique could be used to form almost any required pattern of metal on a substrate, the reaction bond being sufficiently strong to withstand the cutting operation.

(ii) Bio-medical applications - Several million artificialor prosthetic parts are implanted into individuals each year. of these many involve ceramics, particularly alumina, with PSZ presently under investigation for its bio-compatibility. Metals used include stainless steels, Ti and $\mathrm{Ti}$ alloys and often noble metals, particularly $\mathrm{Pt}$ or $\operatorname{Ir} / 12 \%$.

Vacuum-tight seals can often be required between these materials, 
particularly in cases where electrical feed-through connections are required into circuitry and components to be implanted. In such cases of course, the ceramic-metal joining process must be just as biocompatible as the materials themselves. The direct nature of reaction bonding, with its lack of any intermediary substances between metal and ceramic, gives it a special advantage in this area. The inert noble metals are especially suitable for many bio-medical applications, used

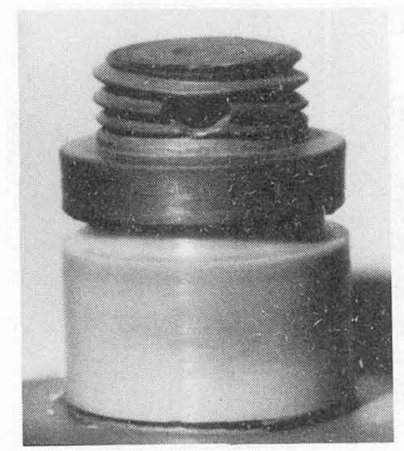

Fig.2. Materials to be used in bio-medical devices, such as titanium and PSZ, may need to be joined via noble metal interlayers. Here a PSZ insulator is joined to a titanium alloy case on on side, and a screw terminal on the other, via gold foil interlayers.

either on their own as connectors or lead-through wires, or as we have found, as interlayer metals to facilitate bonding of non-noble metals like titanium.

Figure 2 shows a test piece of a PSZ insulator bonded between a titanium alloy case on one side, and a screw terminal on the other, both bonds being made via a thin foil of noble metal, in this case gold. This bond combination has a bend strength of 102MPa, (formed under conditions of 1 hour at $890^{\circ} \mathrm{C}$, contact pressure 7MPa). Similar bonds can be formed using platinum if required.

(iii) Structural Applications - Ceramics are increasingly being considered for use in structural applications, where the properties required are toughness, resistance to wear, corrosion and erosion, and ability to tolerate high temperature operation.

The ceramics of interest here are PSZ, silicon nitrides, silicon carbide and alumina. The structural applications include extrusion dies, spray nozzles, wear pads, pump parts, bearings and components for gas turbine and diesel engines. In all these areas, a mean of attachment of ceramic to metal is nearly always required. For many applications however, the traditional techniques of shrink-fitting, mechanical fastening, or low temperature adhesives or cements are inadequate, and now joining processes must be developed which can satisfy the demands of the new application areas.

Our investigations have been orientated towards studying the reaction bonding behaviour of the materials likely to be involved in these structural applications. As ceramics, PSZ and alumina bond readily to a large range of metals, although as described above, an interlayer of a ductile metal such as copper is generally necessary to obtain a strong bond with ferrous metals. Alumina will generally form the strongest bonds of this type, up to $167 \mathrm{MPa}$ for the combination stainless steel$\mathrm{Cu}-\mathrm{Al}_{2} \mathrm{O}_{3}$ for example, (formed at $1040^{\circ} \mathrm{C}$ for 4 hours at $4 \mathrm{MPa}$ contact pressure, tested by 4 point bend). PSZ also bonds well, but bond 
strengths are limited by the restrictions on bonding temperature for PSZ, i.e. for maximum long-term stability, this material is not recommended to be heated for long periods above $\sim 800^{\circ} \mathrm{C} / 13 /$. At this bonding temperature the strength of bonds formed between PSZ (2) and

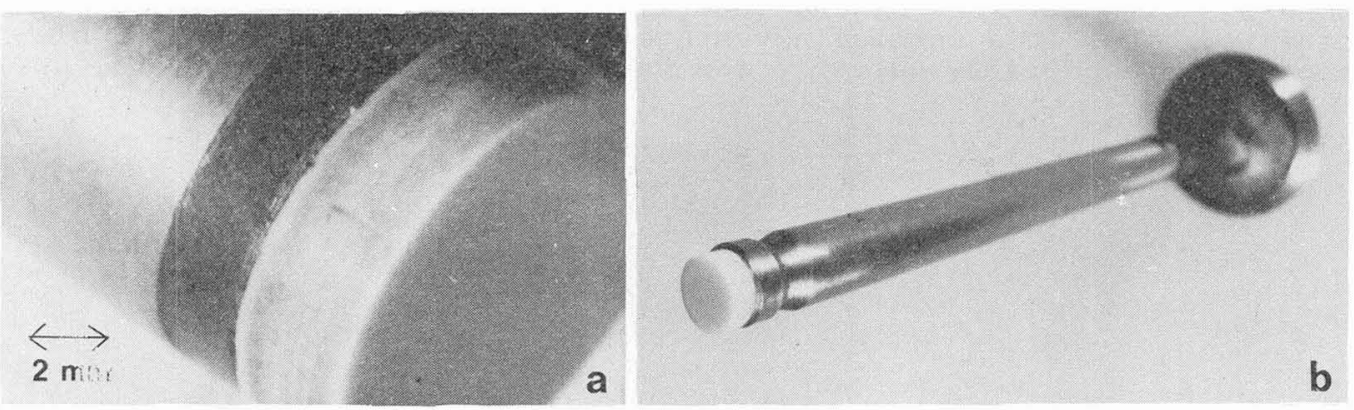

Fig.3. Copper is a useful interiayer material, facilitating bonóing between a wide range of materials:

(a) Aluminium joined to PSZ via copper

(b) A steel alloy engine valve, bonded at the tip to PSZ via a copper interlayer.

copper is around 70MPa (3).

Bonds between the silicon nitride materials and copper have also been attempted, although this work is at an early stage. These materials are also restricted in bonding temperature, due to the presence of glassy phases within the ceramic which limit their maximum operating temperature to $\sim 800^{\circ} \mathrm{C}$. Maximum bond strength obtained so far for SYALON-COpper is $90 \mathrm{MPa}$, bonded under conditions of $870^{\circ} \mathrm{C}$, for 1 hour at $5 \mathrm{MPa}$ contact pressure (4).

Much has been claimed about the prospects for ceramics in internal combustion engines, with the emphasis being on the superior physical and mechanical properties offered by these materials in replacing metal components. One important factor however, which may impede acceptance of ceramics for engine components, is their substantially higher cost, the fabrication of complex shapes in ceramic being inherently more costly than for metals. A large part of this extra cost is incurred in the necessary machining of ceramic components to the required tolerance which by its nature is more expensive for ceramics than for metals. There is therefore a need to restrict the use of ceramics to those areas where their superior properties are required, i.e. areas of high wear and thermal stress. If metal and ceramic are to be used in combination, then inevitably a demand is created for suitable metal-ceramic joining techniques. The engine application is most severe, in that the joints in most cases must perform reliably under considerable applied stress.

Possible areas where reaction bonding could be applicable to engine components are piston caps and valve stem tips. The purpose of a ceramic cap on either an aluminium or cast iron piston is to act as a load-bearing heat shield, while a valve tip is an area suffering high wear.

(2) PSZ here refers to MgO partially stab. $\mathrm{ZrO}_{2}$, as supplied by Nilcra Ceramics Pty lutd (Australia).

(3) Sandwich type bonds formed from PSz rod $13 \mathrm{~mm}$ dia., and cu discs $0.5 \mathrm{~mm}$ thick, tested by 4 point bend. 
In these applications, a 2-stage process may be required, for example, a direct reaction bond formed between the ceramic and a copper layer (such as foil), followed by some form of metal-metal joining process between the copper and the piston or valve metal, e.g. brazing or even solid-phase bonding. Figure $3 a$ shows an aluminium alloy-copper-PSz bond, made in this way. The Cu-Al joint is solid-state, heated at $500^{\circ} \mathrm{C}$ for 2 hours at $2 \mathrm{MPa}$ contact pressure.

A one-stage process may be possible in certain cases. Figure $3 b$ shows a steel valve stem, which has been bonded in one heating cycle to a PSz tip via a copper foil interlayer.

\section{Conclusion}

Being a direct, solid-state process, reaction bonding can be used to join a wide variety of ceramics to metals. Interlayers of suitable metals can be used to facilitate bonding in those cases where strong, reliable bonds cannot readily be formed directly. The versatility of the process, in both range of materials which can be joined and flexibility of bonding conditions, lends it to application areas as diverse as electronics, bio-medicine and engine components.

\section{REFERENCES}

/1/ Tylecote, R.F., "The Soliä thase Welding of Metals" (Edward Arnold Ltd, London 1968).

/2/ Fenn, R., Metallurgist and Materials Technologist 16 (1984) 341.

/3/ De Bruin, H.J., Moodie, A.F., Warble, C.E., J. Mat. Sci. 7 (1972)

909 .

/4/ Bailey, F.P., Borbidge, W.E., Mat. Sci. Res. 14 (1981) 525.

/5/ Allen, R.V., Borbidge, W.E., J. Mat. Sci. 18 (1983) 2835.

$/ 6 /$ Bailey, F.P., Black, K.J.T., J. Mat. Sci. 13 (1978) 1045.

/7/ Warble, C.E., Cowley, J.M., Proc. 41st. Ann. Meeting of the Electron Microscopy Soc. of America (1983). Ed. Bailey, G.W.

/8/ Nicholas, N.G., Crispin, R.M., J. Mat. Sci. 17 (1982) 3347.

$19 /$ Steinleitner, G., "Joining of ceramics, glass and metal", DVS Berichte 66 (1980) 100 .

/10/ Katz, G., Thin Solid Films 33 (1976) 99.

/11/ Keser, H., Schuler, C., Wittmer, M., "Joining of ceramics, glass and metal", DVS Berichte 66 (1980) 33 .

/12/ Hench, L.L., Science 208 (1980) 826.

/13/ Nilcra Ceramics Pty. Ltd. (Australia). Technical Data sheet. 